\title{
Rapid degradation of bisphenol A using air as the oxidant catalyzed by polynuclear phthalocyanine complexes under visible light irradiation
}

\author{
Chao Tai, Guibin Jiang*, Jingfu Liu, Qunfang Zhou, Jiyan Liu \\ Key Laboratory of Environmental Chemistry and Ecotoxicology, Research Center for Eco-Environmental Sciences, \\ Chinese Academy of Sciences, P.O. Box 2871, Beijing 100085, China
}

Received 27 August 2004; received in revised form 2 December 2004; accepted 15 December 2004

Available online 21 January 2005

\begin{abstract}
The photocatalytic dechlorination and destruction of bisphenol A (BPA) using air as the oxidant catalyzed by polynuclear phthalocyanine complexes under visible light irradiation have been studied. Among the four complexes studied (FePPc, CuPPc, ZnPPc, AlPPc), ZnPPc and AlPPc show high catalytic activities. Under ambient conditions of temperature and pressure, an initial BPA concentration of $1 \mathrm{mM}$ in water was completely converted to $\mathrm{CO}_{2}$ and carboxylic acid in $20 \mathrm{~min}$ with a catalyst/substrate molar ratio of 2:100 using a $100 \mathrm{~W}$ tungsten lamp as the light source. Six HPLC peaks indicating intermediate products appeared in chromatograms monitored at $254 \mathrm{~nm}$. Oxalic acid and maleic acid were detected as their methyl esters in the resulting solution by GC-MS after treated with trimethylsulfonium hydroxide. TOC measurements indicated that $21.3 \%$ of the carbon was mineralized after an hour of reaction. When sunlight was used as the light source, BPA could also be degraded efficiently. Full conversion of BPA and its intermediate products were observed in 40 min without stirring and blowing air. The results of ESR measurements suggested that the reaction possibly proceeded via the pathway with singlet oxygen. A possible reaction sequence of the degradation of BPA was proposed. The influences of catalyst/substrate molar ratio, flow rate of the air, and $\mathrm{pH}$ were investigated.
\end{abstract}

(C) 2004 Elsevier B.V. All rights reserved.

Keywords: Bisphenol A; Photocatalysis; Degradation; Visible light; Singlet oxygen; Sunlight

\section{Introduction}

Recently, several types of environmental pollutants referred to as endocrine disruptors (EDs) have been suggested to be associated with abnormal sexual development and abnormal feminizing responses of animals in a number of reports [1]. Bisphenol A [2,2-bis(4-hydroxyphenyl) propane or BPA], which is a compound widely used as the monomer for the production of polycarbonate plastics and as a major component of epoxy resin, is widely suspected to act as an ED $[2,3]$. The BPA originating from the plastic products and various wastewaters has been found in rivers, lakes and ocean

\footnotetext{
* Corresponding author. Tel.: +86 106284 9334; fax: +86 1062849179 E-mail address: gbjiang@mail.rcees.ac.cn (G. Jiang).
}

[4-6]. The adverse influence of BPA on aquatic animal has been of great concern $[7,8]$.

Various methods have been suggested to remove BPA from water, such as biological method [9-12], chemical oxidation [13-14], electrochemical oxidation [15] and photocatalytic method $[16,17]$. Among them, photocatalysis has been the focus of numerous investigations in recent years for the potential use sunlight as the energy source to degrade pollutions $[18,19]$. As the most widely studied material in the field of photocatalysis, $\mathrm{TiO}_{2}$ has been used to degrade BPA successfully $[16,17]$. However, $\mathrm{TiO}_{2}$ can only be excited by high energy UV radiation with a wavelength of no longer than $387.5 \mathrm{~nm}$ for its high band gap $\left(E_{\mathrm{g}} \approx 3.2 \mathrm{eV}\right)$. This practically rules out the use of sunlight as the energy source [20].

Since metallophthalocyanine complexes have intense absorption bands in the longer wavelength region of the vis- 


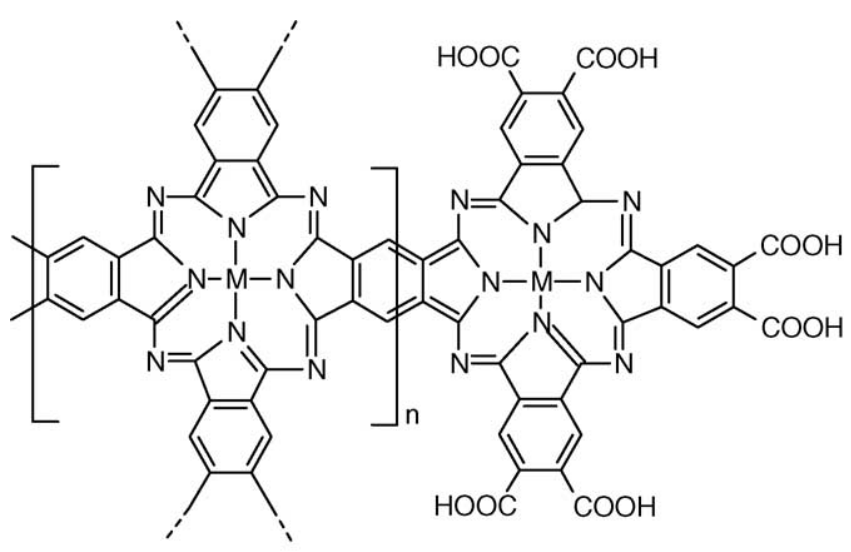

$\mathrm{M}=\mathrm{Fe}, \mathrm{Cu}, \mathrm{Zn}, \mathrm{Al}$

Fig. 1. Structure of the polynuclear zinc polyphthalocyanine.

ible light in a solar spectrum and high quantum yield for photoexcited triplet state $(\Phi>0.40)$ with a long lifetime, they are attractive sensitizers for photoreduction of water and carbon dioxide, as well as a photodynamic therapy [21]. The photooxidation of substrates by oxygen in the presence of visible light activation of photosensitizers is of increasing interest. Various photosensitizers, such as dyes, porphyrines and phthalocyanines, have been used to be photosensitizers to oxidize thiols, sulfide, thioethers, phenol and monochlorophenols [22-26] Recently, polynuclear metal phthalocyanine complexes have attracted attentions because of their increased catalytic properties compared to mononuclear one $[27,28]$. Some polynuclear cobalt phthalocyanine complexes exhibit a much higher specific activity to activate the oxygen than the mononuclear compound in the oxidation of sulfide [29]. As the photocatalyst in the photooxidation of sulfide, thiosulfate, and phenol, the catalytic activity per mole of the polynuclear zinc and aluminium complexes is two to five times higher than that of the respective mononuclear phthalocyanine complexes [30,31].

Here we report rapid destruction of BPA and its intermediate products using air as the oxidant catalyzed by polynuclear phthalocyanine complexes under visible light irradiation. The major goals of this study were to examine the catalytic activity of different complexes of PPc (Fig. 1) under visible light irradiation for the degradation of BPA; and to optimize the operating conditions by investigating the effect of catalyst/substrate molar ratio, flow rate of the air and $\mathrm{pH}$.

\section{Materials and methods}

\subsection{Materials}

BPA (99\%) was purchased from Acros and used without further purification. Triethylsulfonium hydroxide was obtained from Tokyo Kasi. Polynuclear phthalocyanine com- plexes were synthesized according to the published method $[32,33]$. The water used in all experiments was purified with a Milli-Q water ion-exchange system.

\subsection{Preparation and characterization of the catalysts}

$9.17 \mathrm{mmol}$ 1,2,4,5-benzeneeracarboxylic dianhydride, $5 \mathrm{mmol}$ metal chloride, $24.5 \mathrm{mmol}$ urea, $0.73 \mathrm{mmol}$ ammonium molybdate were mixed and heated for $3 \mathrm{~h}$ at $250^{\circ} \mathrm{C}$ in a flask. The powdered reaction mixture was extracted for $20 \mathrm{~h}$ with dimethylsulfoxide in a Soxhlet apparatus and washed with acetone. Then the product was stirred with $300 \mathrm{ml}$ of $3 \mathrm{~mol}^{-1}$ hydrochloric acid for $16 \mathrm{~h}$ at room temperature and washed with water and acetone. The end imide groups in the polynuclear complexes were transformed into carboxylic groups upon heating the mixture for $5 \mathrm{~h}$ using $15 \mathrm{ml}$ solution contain $1.2 \mathrm{~g}$ sodium hydroxide and $6 \mathrm{~g}$ sodium chloride. After filtration, the product was acidified with $2 \mathrm{moll}^{-1}$ hydrochloric acid and isolated and dried. Dark green products were prepared with a yield of 30-40\%. FT-IR spectra were recorded on a PE2000 spectrophotometer, using $\mathrm{KBr}$ pellets. Elemental analyses were carried on Flash EA1112 elemental analyzer. The metal content was determined by flame atomic adsorption spectrophotometric method after treatment by conc. sulfuric and conc. nitric acid [32]. The UV-vis absorption spectra of polynuclear phthalocyanine complexes were shown in Fig. 2. Their UV-vis spectras show a maximum adsorption at $680-690 \mathrm{~nm}$ and a shoulder at $615-630 \mathrm{~nm}$. The complexes synthesized different times gave the same results, suggesting the synthetic reproduction is very good. From the results of UV-vis spectra of the complexes, it can be seen that the aggregation of polynuclear phthalocyanine complexes in solution is a smaller extent than that of mononuclear complexes to receive a higher catalytic activity than mononuclear ones [34].

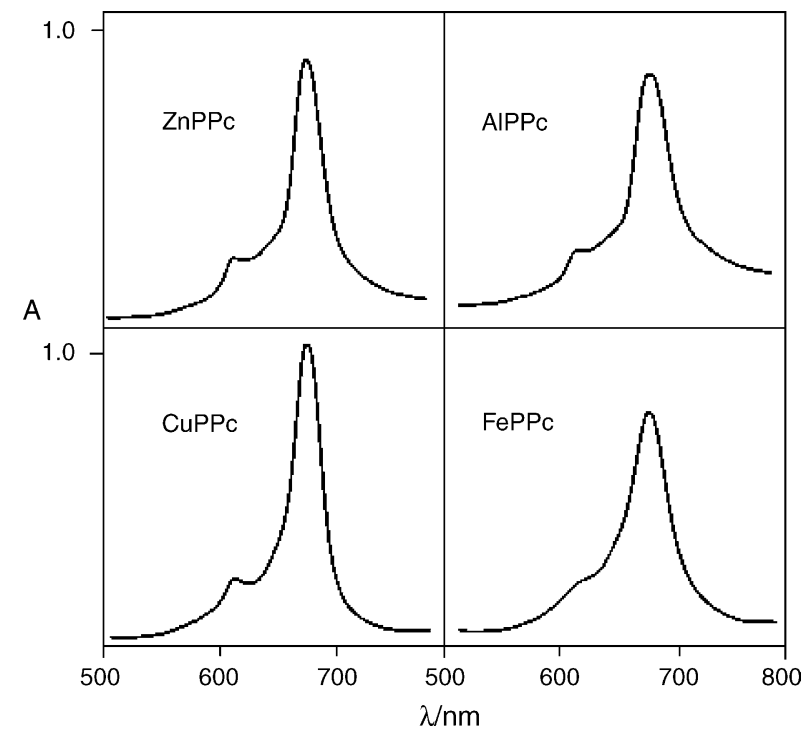

Fig. 2. The UV-vis spectra of ZnPPc, AlPPc, CuPPc and FePPc in water at $0.015 \mathrm{mmol}^{-1}, \mathrm{pH}=11$. 


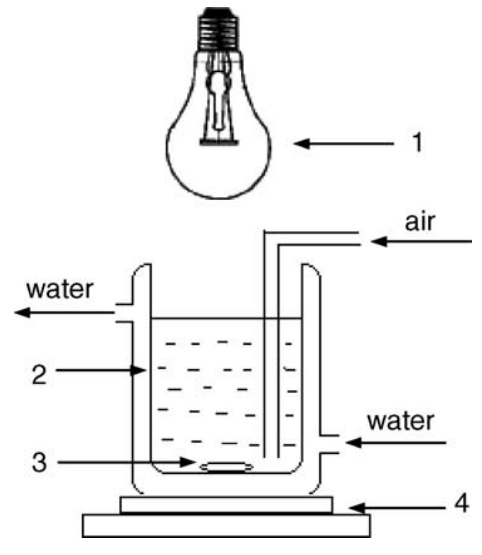

Fig. 3. Schematic illustration of the photoreactor: (1) tungsten lamp; (2) cylindrical Pyrex flask surrounded by a circulating water jacket; (3) stirrer; (4) magnetic stirrer.

\subsection{Method}

The irradiation source was a $100 \mathrm{~W}$ tungsten lamp positioned above a cylindrical vessel (diameter $4 \mathrm{~cm}$, high $6 \mathrm{~cm}$ ) surrounded by a circulating water jacket to cool the reaction solution (Fig. 3). $1.5 \mathrm{ml}$ of $0.35 \mathrm{mmol}^{-1} \mathrm{ZnPPc}$ and $2.5 \mathrm{ml}$ of $10 \mathrm{mmol}^{-1} \mathrm{BPA}$ (in $0.1 \mathrm{~mol}^{-1} \mathrm{NaOH}$ ) were added then diluted to $25 \mathrm{ml}$. The photocatalytic reaction proceeded with the air blowing in at $200 \mathrm{ml} / \mathrm{min}$ under magnetic stirring. The degradation of BPA under sunlight irradiation was carried out in a culture dish (diameter $8 \mathrm{~cm}$ ) without stirring and blowing air, the irradiation intensity of the sunlight was $608.3 \mu \mathrm{mol} \mathrm{s}^{-1} \mathrm{~m}^{-2}$. One milliliter of illuminated samples were removed from the photoreactor periodically and diluted to $5 \mathrm{ml}$ and analyzed by HPLC.

\subsubsection{Analytical methods}

The HPLC equipment used was an Agilent 1100LC including a BinPump and a UV-vis detector. The UV-vis detector was set $254 \mathrm{~nm}$ wavelength. An Agilent Zorbax Eclipse $\mathrm{XDB}_{-} \mathrm{C}_{18}$ column $(150 \mathrm{~mm} \times 4.6 \mathrm{~mm}$, particle size $5 \mu \mathrm{m})$ was used as analytical column. LC separation of BPA and its degradative products was conducted by using a mixture of acetonitrile and water (the $\mathrm{pH}$ was adjusted to 4 with trifluoroacetic acid) as mobile phase at a flow rate of $1.0 \mathrm{ml} / \mathrm{min}$. The gradient profile was: increase from $10 \%$ to $50 \%$ acetonitrile in $0-15 \mathrm{~min}$ and then keep $50 \%$ for $5 \mathrm{~min}$. A personal computer equipped with an Agilent ChemStation program for LC systems was used to process chromatographic data.

The final products of the degradation of BPA are identified as follows: the reaction mixture was evaporated under vacuum. The residue was dissolved in $3 \mathrm{~mol}^{-1} \mathrm{HCl}$ to produce a $\mathrm{pH}<2$. The resulting solution was saturated with $\mathrm{NaCl}$ and extracted with diethyl ether $(3 \times 10 \mathrm{ml})$. The combined ether extracts were dried with anhydrous sodium sulfate and the ether was evaporated under vacuum. The residue was dissolved in methanol and treated with trimethylsulfonium hydroxide and analyzed by GC-MS with an Agilent 6890 gas chromatography coupled with 5973 mass spectrometry detection. The separation was performed with a $60 \mathrm{~m}$ length, $0.25 \mathrm{~mm}$ i.d. fused silica column HP-5MS with $0.25 \mathrm{~mm}$ film thickness, utilizing with helium as carrier gas at a flow rate of $1.0 \mathrm{ml} / \mathrm{min}$ in a constant flow mode. The oven temperature program used was as follow: held at $80^{\circ} \mathrm{C}$ for $6 \mathrm{~min}$, and ramped to $300{ }^{\circ} \mathrm{C}$ at $10^{\circ} \mathrm{C} / \mathrm{min}$. Electron impact ionization at $70 \mathrm{eV}$ was used. The injection was operated in splitless mode at a temperature of $300{ }^{\circ} \mathrm{C}$, and purge flow was $50 \mathrm{ml} / \mathrm{min}$ until $0.75 \mathrm{~min}$. A $1 \mu \mathrm{l}$ aliquot of sample was injected. TOC measurements were carried out on an Apollo 9000 TOC Analyzer (Tekmar-Dohrmann Co., USA). ESR measurements were carried out on a Bruker ESP 300E Electron Spin Resonance Spectrometer.

\section{Results and discussion}

\subsection{Characterization of the catalysts}

FT-IR bands of the catalysts are listed in Table 1. The catalysts show absorption bands at 1620-1630, 1306-1310, 1067-1095, 900-910, and 745-750, which are the typical absorptions of phthalocyanine skeleton [32]. The presence of absorption bands near $1770(\nu-\mathrm{C}=\mathrm{O})$ and $3300(\nu-\mathrm{OH})$ indicate the presence of carboxylic end groups, which is also proved by higher dissolvability of the catalysts in alkaline solution than in acidic and neutral solution. Results of elemental analyses are listed in Table 2 . The $\mathrm{C} / \mathrm{N}$ ratios of the elemental analysis of the complexes, which are sensitive to changes in the number of phthalocyanine units in polynuclear complexes [32], are in the range of 2.54-2.88. The results indicate the average number of phthalocyanine units in the complexes lies

Table 1

FT-IR data of PPcs (in KBr)

\begin{tabular}{lll}
\hline FePPc $(732 \mathrm{~s}, 745 \mathrm{~s}, 799 \mathrm{~m})$ & CuPPc $(738 \mathrm{~m}, 752 \mathrm{~s}, 779 \mathrm{w})$ & ZnPPc $(726 \mathrm{~s}, 740 \mathrm{sh}, 773 \mathrm{w})$ \\
\hline $900 \mathrm{w}$ & $903 \mathrm{w}$ & $907 \mathrm{w}$ \\
$1089 \mathrm{~s}, 1133 \mathrm{w}$ & $1095 \mathrm{~m}, 1120 \mathrm{sh}$ & $1093 \mathrm{~s}, 1126 \mathrm{sh}$ \\
$1310 \mathrm{~s}$ & $1306 \mathrm{~m}$ & $1308 \mathrm{~m}$ \\
$1620 \mathrm{~m}$ & $1625 \mathrm{sh}$ & $1627 \mathrm{~m}$ \\
$1713 \mathrm{~s}$ & $1723 \mathrm{~s}$ & $1710 \mathrm{~s}$ \\
$1767 \mathrm{~m}$ & $1775 \mathrm{~m}$ & $1763 \mathrm{~m}$ \\
$3152-3418 \mathrm{w}$ & $3028-3425 \mathrm{w}$ & $3191-3439 \mathrm{w}$ \\
\hline
\end{tabular}

Frequencies in $\mathrm{cm}^{-1}$; intensities: $\mathrm{s}=$ strong, $\mathrm{m}=$ medium, $\mathrm{w}=$ weak, $\mathrm{sh}=$ shoulder. 
Table 2

Elemental analyses results of PPcs

\begin{tabular}{lllllll}
\hline Samples & $\mathrm{C} \%$ & $\mathrm{~N} \%$ & $\mathrm{H} \%$ & Metal\% & $\begin{array}{l}\mathrm{C} / \mathrm{N} \\
\text { ratio }\end{array}$ & $\begin{array}{l}\text { Content of } \\
\text { Pc units } \\
\left(\mathrm{mmol} \mathrm{g}^{-1}\right)\end{array}$ \\
\hline FePPc & 47.97 & 18.85 & 2.67 & 4.4 & 2.54 & 0.78 \\
CuPPc & 42.82 & 14.85 & 2.59 & 7.0 & 2.88 & 1.09 \\
ZnPPc & 43.83 & 16.84 & 2.15 & 4.6 & 2.60 & 0.71 \\
AlPPc & 47.76 & 18.72 & 2.57 & 3.1 & 2.55 & 1.14 \\
\hline
\end{tabular}

between 9 and 16 . Since it is difficult to determine the definite molecular weight of the complexes, the concentration of the catalyst are defined as the concentration of phthalocyanine units, which can be calculated by the content of the metals (Table 2).

\subsection{Degradative behavior}

Among the four complexes studied (FePPc, CuPPc, ZnPPc, AlPPc), ZnPPc and AlPPc show high catalytic activities. Fig. 4 shows the photodegradation of BPA catalyzed by ZnPPc and AlPPc. It can be seen that ZnPPc has higher catalytic activity than AlPPc. The HPLC chromatograms (Fig. 5) of the samples, taken from the reactor during the photocatalytic process, show the disappearance of BPA (peak 7) and formation of its degradation products peaks (peaks 1-6). Fig. 6 shows the time dependences of the amounts of the intermediate products formed during the photocatalytic reaction. The vertical axis in Fig. 6 corresponds to the heights of the absorption peaks normalized to the height of the initial BPA peak. Peaks $2-6$ reached a maximum concentration in $5 \mathrm{~min}$, then decreased and disappeared in no longer than $20 \mathrm{~min}$. Peak 1 reached its maximum height in $30 \mathrm{~min}$ and then decreased a little. Control experiments with ZnPPc in the dark or under visible light irradiation without $\mathrm{ZnPPc}$ indicated no degradation of BPA. It was found that the adsorption of

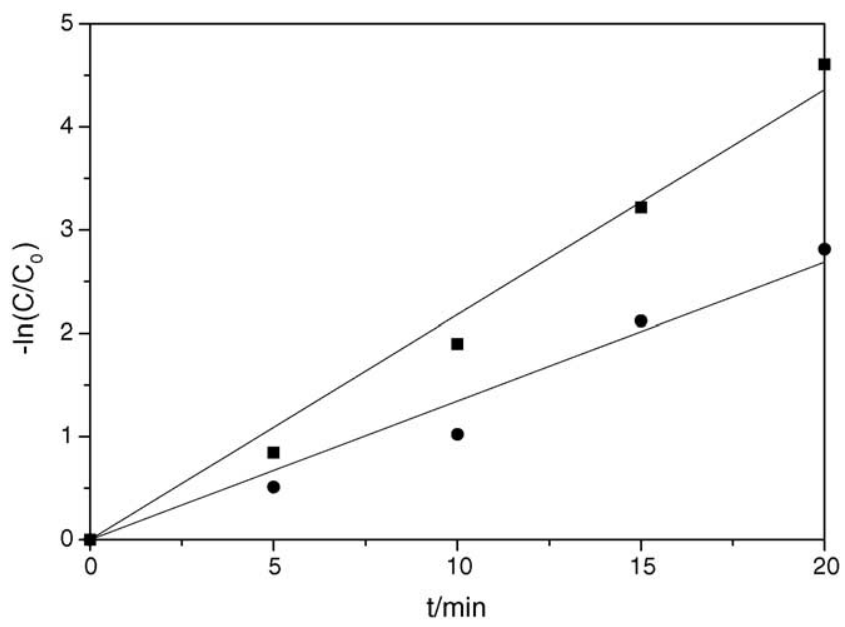

Fig. 4. The photodegradation of BPA catalyzed by ZnPPc and AlPPc, catalyst $/$ substrate $=2 \%,[B P A]_{0}=1 \mathrm{mM}, \mathrm{pH} 12$, the flow rate of the air was $200 \mathrm{ml} / \mathrm{min}$, the $100 \mathrm{~W}$ tungsten lamp was used as the visible light source. (匹) $\mathrm{ZnPPc} ;(\bullet) \mathrm{AlPPc}$.

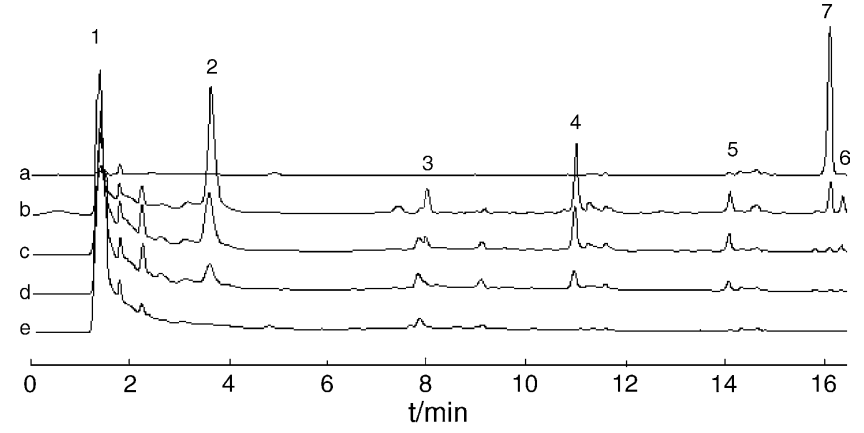

Fig. 5. Evolution of HPLC chromatograms during the photocatalytic treatment of a BPA solution. Catalyst $/$ substrate $=2 \%,[\mathrm{BPA}]_{0}=1 \mathrm{mM}, \mathrm{pH} 12$, the flow rate of the air was $200 \mathrm{ml} / \mathrm{min}$, the $100 \mathrm{~W}$ tungsten lamp was used as the visible light source. (a) $0 \mathrm{~min}$; (b) $5 \mathrm{~min}$; (c) $10 \mathrm{~min}$; (d) $15 \mathrm{~min}$; (e) $20 \mathrm{~min}$.

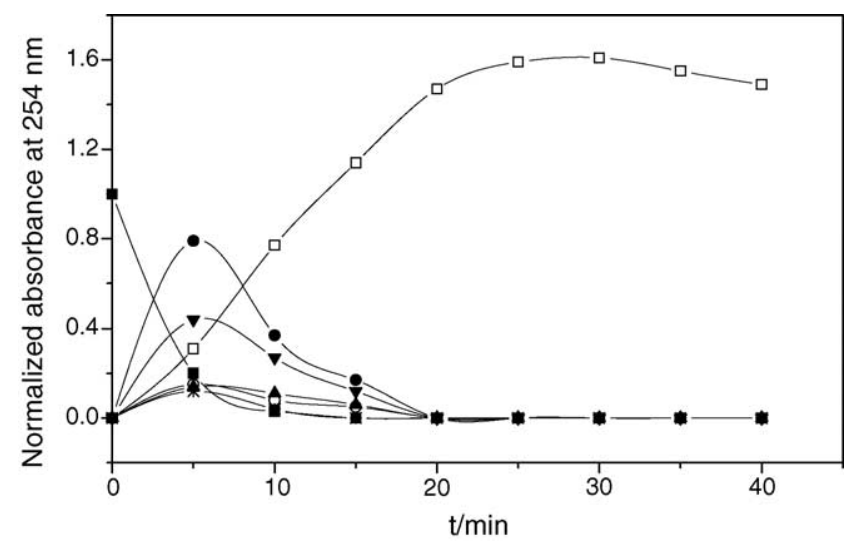

Fig. 6. Time course of degradation of BPA and the further destruction of the intermediate products. Catalyst/substrate $=2 \%,[\mathrm{BPA}]_{0}=1 \mathrm{mM}, \mathrm{pH} 12$, the flow rate of the air was $200 \mathrm{ml} / \mathrm{min}$, the $100 \mathrm{~W}$ tungsten lamp was used as the visible light source. (ם) Peak 1; $(\bullet)$ peak 2; $\bigcirc)$ peak 3; ( $)$ peak 4; $(\mathbf{\Delta})$ peak 5 ; (*) peak 6 ; $(\square)$ peak 7 .

$\mathrm{ZnPPc}$ and AlPPc at $680 \mathrm{~nm}$ decreased during the catalytic reaction, which indicated that the complexes also degraded. About $46 \%$ of ZnPPc and $57 \%$ of AlPPc were degraded in the first $5 \mathrm{~min}$. After a reaction of $30 \mathrm{~min}$, about $87 \%$ of $\mathrm{ZnPPc}$ and $96 \%$ AlPPc were found to disappeared.

\subsection{Analyses of degradation products}

Peaks 1-5 had retention times shorter than BPA, which indicates that they are more polar than BPA. Because peak 1 could not disappeared completely in our prescriptive time, it was necessary to identify what kind of compound it was. Peak 1 could be even eluted from the column with water $(\mathrm{pH}=4)$ in $2 \mathrm{~min}$, which indicated that it was possibly carboxylic acids. GC-MS was used to identify the intermediate products after treat with trimethylsulfonium hydroxide $[35,36]$. Two organic acids were detected as their methyl esters: oxalic acid $\mathbf{1}$ and maleic acid $\mathbf{2}$. Hydroquinone $\mathbf{3}$ and 4-isopropenyl-phenol 4 were also detected. GC-MS data of the products of degradation of BPA was show in Table 3 . TOC measurements indicated that $21.3 \%$ of the carbon was 
Table 3

GC-MS data of the products of degradation of BPA

\begin{tabular}{llll}
\hline Compounds & Retention time $(\mathrm{min})$ & Derivatized product & Mass spectrum $m / z$ (relative intensity) \\
\hline Oxalic acid 1 & 6.88 & Oxalic acid, dimethyl ester & 59(100), 45(36.1), 29 (25.6), 31 (4.9), 118 (3.6), 30 (2.2) \\
Maleic acid 2 & 11.44 & Maleic acid, dimethyl ester & $113(100), 85(98.6), 59(49.1), 53(37), 114(14.6)$, \\
Hydroquinone 3 & 16.36 & - & $110(100), 81(39.7), 53(32.5), 55(23.5), 39(19.1)$ \\
4-Isopropenyl-phenol 4 & 16.80 & - & $134(100), 119(86.1), 91(40.4), 65(24.6), 133(22.0)$ \\
\hline
\end{tabular}

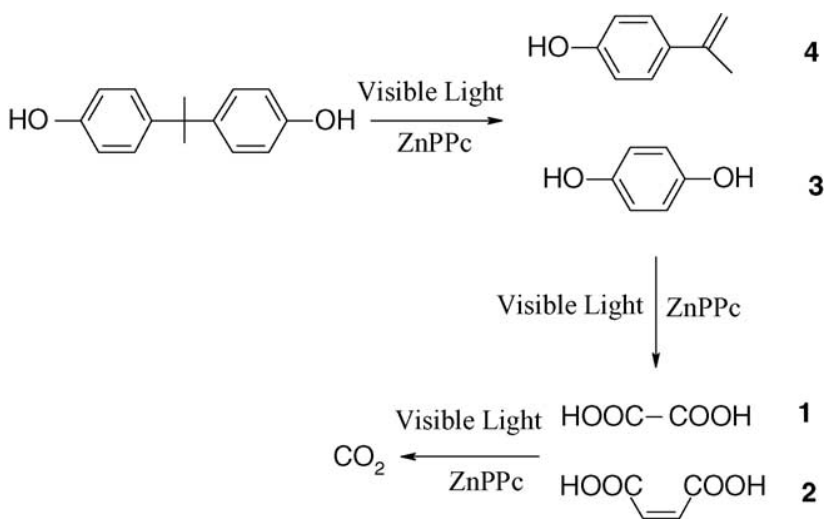

Fig. 7. Schematic representation of possible reaction sequence of the degradation of BPA.

mineralized after an hour of reaction. From the results above, a possible reaction sequence of the degradation of BPA was proposed (Fig. 7).

\subsection{Degradation mechanism}

The degradation of BPA was extensively inhibited by the addition of aqueous sodium azide, a singlet oxygen scavenger, to the solution, such depression was not observed by the addition of 3,5-di-tert-butyl-4-hydroxytoluene, a superoxide scanvenger [22]. The ESR technique was also used to gain insight into the nature of radicals formed during the photodegradation with 2,2,6,6-tetramethylpiperidine (TEMP) as probe for the singlet oxygen. Fig. 8 illustrates the ESR spectra in different conditions. No signals of significant intensity were observed when the experiments were run in the dark or in the absence of ZnPPc. However, when the system was irradiated with visible light in the presence of $\mathrm{ZnPPc}$, the ESR signal displayed a 1:1:1 triplet signal characteristic of TEMPO obtained by reaction with singlet oxygen [37]. The results suggested that the reaction possibly proceeded via the pathway with singlet oxygen.

\subsection{Determination of rate constants}

Singlet oxygen is very short-lived species. Its concentration may be considered in a quasistationary state. In our experiments, the solution was continuously saturated with air, the concentration of $\mathrm{ZnPPc}$ and the irradiation intense were constant. In these

$\mathrm{BPA}+{ }^{1} \mathrm{O}_{2} \rightarrow$ products conditions, the degradation of BPA was a pseudo-order reaction. So the rate constant of the BPA degradation (1) might be comparatively determined taking the 2,4,6-trichlorophenol (TCP) as standard. In fact, TCP was chosen because its rate constant of the reaction with singlet oxygen (2) was well established [38] $\left(1.67 \pm 0.07 \times 10^{8}\left(\mathrm{~mol} \mathrm{l}^{-1}\right)^{-1} \mathrm{~s}^{-1}, 25^{\circ} \mathrm{C}\right)$.

$\mathrm{TCP}+{ }^{1} \mathrm{O}_{2} \rightarrow$ products

Assuming that there were no side reaction of BPA and the standard compound TCP, other than the reaction with singlet oxygen, the rates of the two reactions were given by

$\frac{-\mathrm{d}[\mathrm{BPA}]}{\mathrm{d} t}=k_{\mathrm{BPA}}\left[{ }^{1} \mathrm{O}_{2}\right][\mathrm{BPA}]$

$\frac{-\mathrm{d}[\mathrm{TCP}]}{\mathrm{d} t}=k_{\mathrm{TCP}}\left[{ }^{1} \mathrm{O}_{2}\right][\mathrm{TCP}]$

Which can be integrated and combined to give the following equation:

$\ln \left(\frac{[\mathrm{BPA}]_{0}}{[\mathrm{BPA}]_{t}}\right)=\left(\frac{k_{\mathrm{BPA}}}{k_{\mathrm{TCP}}}\right) \times \ln \left(\frac{[\mathrm{TCP}]_{0}}{[\mathrm{TCP}]_{t}}\right)$

where the subscripts 0 and $t$ indicate concentration at the beginning of the experiment and at time $t$, respectively. A plot of $\ln \left([\mathrm{BPA}]_{0} /[\mathrm{BPA}]_{t}\right)$ versus $\ln \left([\mathrm{TCP}]_{0} /[\mathrm{TCP}]_{t}\right)$ thus yields
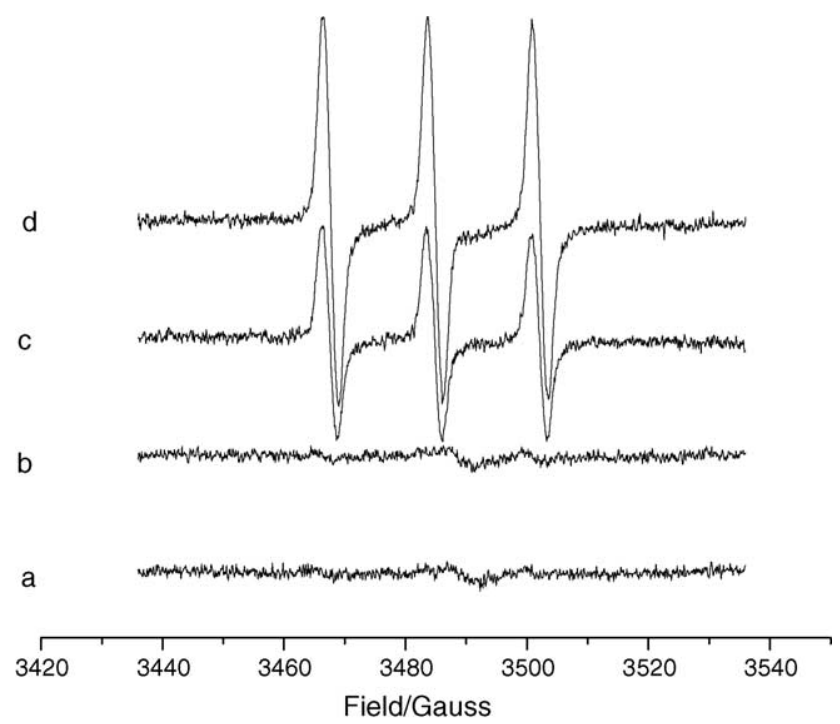

Fig. 8. ESR spectra of solutions under different conditions in the presence of $10 \mathrm{mM}$ TEMP. (a) In the absence of ZnPPc under visible light irradiation; (b) in the presence of $\mathrm{ZnPPc}$ in the dark; (c) in the presence of $\mathrm{ZnPPc}$ under visible light irradiation for $5 \mathrm{~min}$; (d) in the presence of $\mathrm{ZnPPc}$ under visible light irradiation for $10 \mathrm{~min}$. 


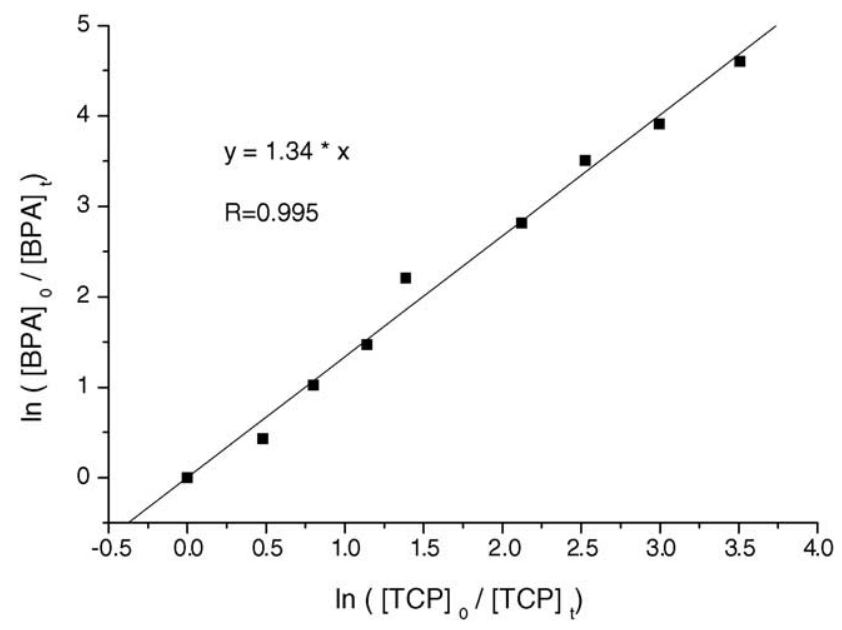

Fig. 9. Determination of rate constants with TCP as the standard.

the rate constant ratio $k_{\mathrm{BPA}, 25^{\circ} \mathrm{C}} 2.23 \times 10^{8}\left(\mathrm{moll}^{-1}\right)^{-1} \mathrm{~s}^{-1}$ (Fig. 9).

\subsection{Effect of experimental conditions}

The reaction parameters that were optimized were the catalyst/substrate molar ratio, flow rate of the air, light source and the $\mathrm{pH}$. The disappearance and the concentration change of the intermediate product 2 , were used to depict the catalytic behavior of $\mathrm{ZnPPc}$ under different conditions.

\subsubsection{Catalyst/substrate molar ratio}

fluence of the catalyst/substrate molar ratio was studied at the $\mathrm{pH} 12$ with a BPA concentration of $1 \mathrm{mmoll}^{-1}$. Fig. 10a shows the influence of catalyst/substrate molar ratio on the disappearance of BPA under a $100 \mathrm{~W}$ tungsten lamp. Fig. 10b shows the concentration change of the intermediate product 2 during the photocatalytic reaction with different catalyst/substrate molar ratio. It can be seen from Fig. 10a that BPA disappears with a catalyst/substrate molar ratio of $0.7 \%$ after $20 \mathrm{~min}$ irradiation. However, with this catalyst/substrate molar ratio, intermediate product 2 cannot be completely further degraded within $20 \mathrm{~min}$ (Fig. 10b). A catalyst/substrate molar ratio of more than $2 \%$ was needed to destruct both BPA and the intermediate products.

\subsubsection{Flow rate of the air}

The concentration of dissolved oxygen in water is about $0.31 \mathrm{mmol}^{-1}$, which is not enough for the degradation of BPA with a concentration of $1 \mathrm{mmoll}^{-1}$. It can be seen from Fig. 11 that only 50\% BPA is degraded in 20 min without air or oxygen blowing in. Air was chosen in our experiments as the oxidant because of its low cost. Fig. 11 shows influence of flow rate of the air on the degradation of BPA and the further destruction of intermediate product 2. BPA was degraded completely in $20 \mathrm{~min}$ with a flow rate of $100 \mathrm{ml} / \mathrm{min}$ (Fig. 11a). Therefore, a flow rate of $200 \mathrm{ml} / \mathrm{min}$ was needed to destruct the intermediate product 2 in $20 \mathrm{~min}$ (Fig. 11b).

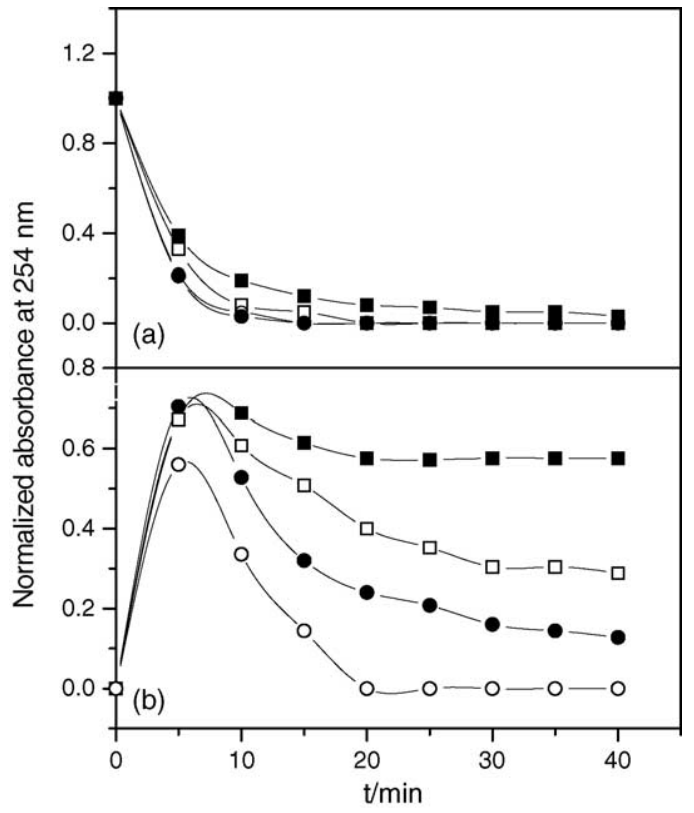

Fig. 10. Effect of the catalyst/substrate molar ratio on the degradation of BPA (a) and the further destruction of the intermediate product 2 (b). $[\mathrm{BPA}]_{0}=1 \mathrm{mM}, \mathrm{pH} 12$, the flow rate of the air was $200 \mathrm{ml} / \mathrm{min}$, the $100 \mathrm{~W}$ tungsten lamp was used as the visible light source. (ם) Catalyst/ substrate $=2 \% ;(\square)$ catalyst $/$ substrate $=1.5 \% ;(\bullet)$ catalyst $/$ substrate $=0.7 \%$; (○) catalyst $/$ substrate $=0.4 \%$.

\subsubsection{Light source}

The influences of the light source on the degradation of BPA were studied. Tungsten lamps of different power were

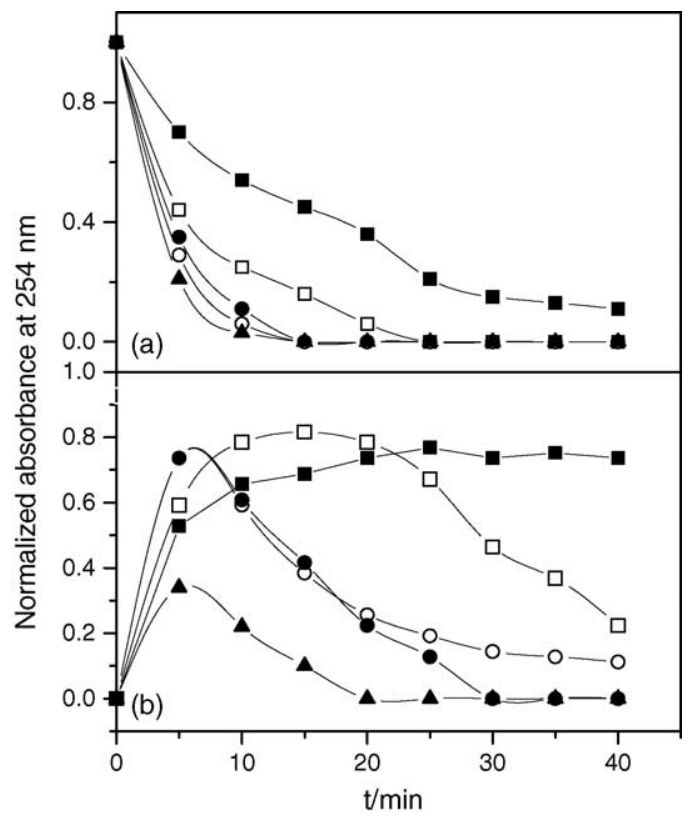

Fig. 11. Effect of flow rate of the air on the degradation of BPA (a) and the further destruction of the intermediate product $2(\mathrm{~b})$. $[\mathrm{BPA}]_{0}=1 \mathrm{mM}, \mathrm{pH}$ 12 , catalyst/substrate $=2 \%$, the $100 \mathrm{~W}$ tungsten lamp was used as the visible

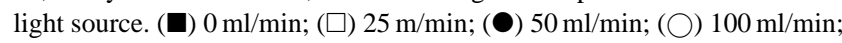
(ム) $200 \mathrm{ml} / \mathrm{min}$. 


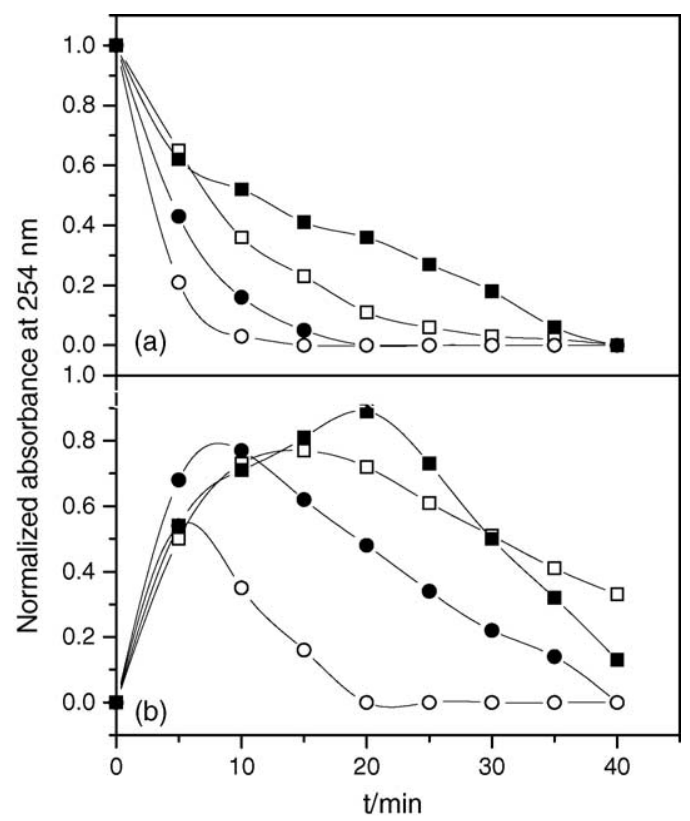

Fig. 12. Effect of the light source on the degradation of BPA (a) and the further destruction of the intermediate product $2(\mathrm{~b})$. $[\mathrm{BPA}]_{0}=1 \mathrm{mM}$, catalyst $/$ substrate $=2 \%$, the flow rate of the air was $200 \mathrm{ml} / \mathrm{min}$. (ロ) Sun light with the irradiation intensity of $608.3 \mu \mathrm{mol} \mathrm{s}^{-1} \mathrm{~m}^{-2}$; ( $\square$ ) $40 \mathrm{~W}$ tungsten lamp with the irradiation intensity of $79.6 \mu \mathrm{mol} \mathrm{s}^{-1} \mathrm{~m}^{-2}$; () $60 \mathrm{~W}$ tungsten lamp with the irradiation intensity of $123.8 \mu \mathrm{mol} \mathrm{s}^{-1} \mathrm{~m}^{-2}$; (○) $100 \mathrm{~W}$ tungsten lamp with the irradiation intensity of $297.3 \mu \mathrm{mol} \mathrm{s}-1 \mathrm{~m}^{-2}$.

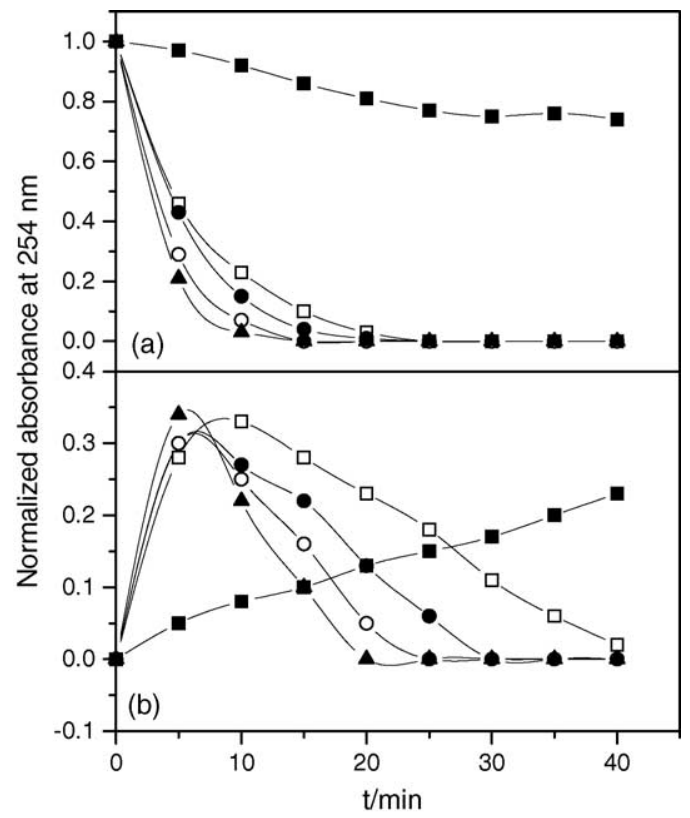

Fig. 13. Effect of the $\mathrm{pH}$ the degradation of BPA (a) and the further destruction of the intermediate product 2 (b). Catalyst/substrate $=2 \%$, $[\mathrm{BPA}]_{0}=1 \mathrm{mM}$, the flow rate of the air was $200 \mathrm{ml} / \mathrm{min}$, the $100 \mathrm{~W}$ tungsten lamp was used as the visible light source. (ם) $\mathrm{pH}=8 ;(\square) \mathrm{pH}=9$; ( $\mathrm{pH}=10 ;(\bigcirc) \mathrm{pH}=11 ;(\boldsymbol{\Lambda}) \mathrm{pH}=12$. used as the light source. The results are shown in Fig. 12 . The rate of BPA degradation increased remarkably with the increase of the lamp power. With a $100 \mathrm{~W}$ tungsten lamp as the light source, BPA and the intermediate products degraded completely in $20 \mathrm{~min}$. More importantly, when sunlight was used as the light source, without stirring and blowing air, BPA (Fig. 12a) and the intermediate products (Fig. 12b) could also be destructed in $40 \mathrm{~min}$. This result made it possible to utilize solar energy in large scale to address environmental needs.

\subsection{4. $p H$}

Since the $\mathrm{pH}$ of industrial aqueous effluents may vary, the $\mathrm{pH}$ dependences of the degradation of BPA and the further destruction of the intermediate products were studied. Phosphonic acid and sodium hydroxide were chosen to adjust the $\mathrm{pH}$ in the range of 8-12. Fig. 13 shows the effect of $\mathrm{pH}$ on the degradation of BPA (Fig. 13a) and the intermediate products (Fig. 13b). No degradation of BPA was detected with the $\mathrm{pH}$ less than 7 . The degradation efficiency increased with the increase of $\mathrm{pH}$. Good degradation efficiency could be obtained at the $\mathrm{pH}$ ranging from 9 to 13 . It is perhaps because the first step of the BPA degradation is the oxidation of the phenolate anion, which presents in the acidic solution in a small amount, leading to the poor conversions [38].

\section{Conclusions}

In conclusion, the $\mathrm{ZnPPc}$ is a promising photocatalyst for the degradation of BPA with the air as the low-cost and environmentally safe oxidant. Under ambient conditions of temperature and pressure, BPA was completely converted to $\mathrm{CO}_{2}$ and carboxylic acid in 20 min using a $100 \mathrm{~W}$ tungsten lamp as the light source. When sunlight was used as the light source, BPA could also be degraded efficiently. Full conversion of BPA and its intermediate products were observed in $40 \mathrm{~min}$ without stirring and blowing air. The results of ESR measurements suggested that the reaction possibly proceeded via the pathway with singlet oxygen. ZnPPc can be synthesized by a clean solid phase synthesis method in high yield in one-step reaction, in which 1,2,4,5-benzeneeracarboxylic dianhydride and urea, two cheap commercial compounds, are used as the precursors. This makes it possible to utilize solar energy in large scale to address environmental needs.

\section{Acknowledgements}

This work was financially supported by the National Natural Science Foundation of China and the Chinese Academy of Sciences (20137010, KZCX2-414). We thank Wenlong Wang (Institute of Chemistry, Chinese Academy of Sciences) for assistance with characterization of the catalysts.

\section{References}

[1] C. Sonnenschein, A.M. Soto, J. Steroid Biochem. Mol. Biol. 65 (1998) 143-150. 
[2] A.V. Krishnan, P. Starhis, S.F. Permuth, L. Tokes, D. Feldman, Endocrinology 132 (1993) 2279-2286.

[3] J.A. Brotons, M.F. Olea-Serrana, M. Villalobos, V. Pedraza, N. Olea, Environ. Health Perspect. 103 (1995) 608-612.

[4] A. Gonzalez-Casado, N. Navas, M. Del-Olmo, J.L. Vilchez, J. Chromatogr. Sci. 36 (1998) 565-569.

[5] T. Yamamoto, A. Yasuhara, Chemosphere 38 (1998) 2569-2576.

[6] K.A. Mountfort, J. Kelly, S.M. Jikells, L. Castle, Food Addit. Contam. 14 (1997) 737-745.

[7] C.A. Staples, P.B. Dom, G.M. Klecka, S.T. O’Block, L.R. Harris, Chemosphere 36 (1998) 2149-2173.

[8] S. Suarez, R.A. Sueiro, J. Garrido, Mutat. Res. 470 (2000) 221-228.

[9] J.H. Kang, F. Kondo, Arch. Environ. Contam. Toxicol. 43 (2002) 265-269.

[10] T. Fukuda, H. Uchida, Y. Takashima, T. Uwajima, T. Kawabata, M. Suzuki, Biochem. Biophys. Res. Commun. 284 (2001) 704-706.

[11] G. Fent, W.J. Hein, M.J. Moendel, R. Kubiak, Chemosphere 51 (2003) 735-746.

[12] Y.J. Xuan, Y. Endo, K. Fujimoto, J. Agric. Food. Chem. 50 (2002) 6575-6578.

[13] J. Sajiki, Environ. Int. 27 (2001) 315-320.

[14] J. Sajiki, J. Yonekubo, Chemosphere 46 (2002) 345-354.

[15] B.A. Boscoletto, F. Gottardi, L. Milan, T. Pannocchia, V. Tartari, M. Tavan, J. Appl. Electrochem. 24 (1994) 1052-1058.

[16] S. Furahori, H. Ihiura, T. Kitaoka, H. Tanaka, Environ. Sci. Technol. 37 (2003) 1048-1051.

[17] Y. Ohko, I. Ando, C. Niwa, T. Tatsuma, T. Yamamura, T. Nakashima, T.Y. Kubota, A. Fujishima, Environ. Sci. Technol. 35 (2001) 2365-2368.

[18] M.C. Blount, D.H. Kim, J.L. Falconer, Environ. Sci. Technol. 35 (2001) 2988-2994.

[19] M.E. Calvo, R.J. Candal, S.A. Bilmes, Environ. Sci. Technol. 35 (2001) 4132-4138.

[20] X.Z. Li, F.B. Li, Environ. Sci. Technol. 35 (2001) 2831-2837.
[21] H. Ali, E.V. Lier, Chem. Rev. 99 (1999) 2379-2450.

[22] K. Kasuga, T. Miyazako, T. Sugimori, M. Handa, Inorg. Chem. Commun. 6 (2003) 807-809.

[23] G. Schneider, D. Wöhrle, W. Spiller, J. Stark, G. Schulz-Ekloff, Photochem. Photobiol. 60 (1994) 333-341.

[24] R. Gerdes, D. Wöhrle, W. Spiller, G. Schneider, G. Schnurpfeil, G. Schulz-Ekloff, J. Photochem. Photobiol. A: Chem. 111 (1997) 65-74.

[25] V. Iliev, L. Prahov, L. Bilyarska, H. Fischer, G. Schulz-Ekloff, D. Wöhrle, L. Petrov, J. Mol. Catal. A: Chem. 151 (2000) 161-170.

[26] K. Ozoemena, N. Kuznetsova, T. Nyokong, J. Photochem. Photobiol. A: Chem. 139 (2001) 217-224.

[27] G. Ramirez, E. Trollund, M. Isaacs, F. Armijo, J. Zagal, J. Costamagna, M.J. Aguirre, Electroanalysis 14 (2002) 540-545.

[28] N.B. Mckcown, J. Mater. Chem. 10 (2000) 1979-1995.

[29] D. Wöhrle, O.N. Suvorova, N. Trombach, E.A. Schupak, R. Gerdes, N.M. Semenov, O. Bartels, A.A. Zakurazhnov, G. Schnurpfeil, O. Hild, A. Wendt, J. Porphyrins Phthalocyanines 5 (2001) 381-389.

[30] V. Iliev, A. Mihaylova, J. Photochem. Photobio. A 149 (2002) 23-30.

[31] V. Iliev, A. Mihaylova, L. Bilyarska, J. Mol. Catal. A 184 (2002) 121-130.

[32] D. Wöhrle, E. Preußner, Makromol. Chem. 186 (1985) 2189-2207.

[33] A. Hadasch, A. Sorokin, A. Rabion, B. Meunier, New J. Chem. 22 (1998) 45-51.

[34] M.A.A. El-Ghaffar, E.A.M. Youssef, N.R. El-Halawany, M.A. Ahmed, Angew. Makromol. Chem. 254 (1998) 1-9.

[35] A. Sorokin, J.L. Séris, B. Meunier, Science 268 (1995) 1163-1166.

[36] S.S. Gupta, M. Stadler, C.A. Noser, A. Ghosh, B. Steinhoff, D. Lenoir, C.P. Horwitz, K.W. Schramm, T.J. Collins, Science 296 (2002) 326-328.

[37] C. Christian, A.W. Rutherford, A. Krieger-Liszkay, FEBS Lett. 532 (2002) 407-410

[38] P.G. Tratnyek, J. Holgné, Environ. Sci. Technol. 25 (1991) 1506-1604. 